\title{
Integrated models of livestock systems for climate change studies. 2 . Intensive systems
}

\author{
J.R. TURNPENNY,* D. J. PARSONS, †A.C.ARMSTRONG, $\ddagger$ J.A. CLAR, A \\ K. COOPER + and A. M. MATTHEWS \\ ${ }^{*}$ School of the Built Environment, University of Nottingham, University Park, Nottingham NG7 2RD, UK, +Silsoe Research \\ Institute, Wrest Park, Silsoe, Bedford MK45 4HS, UK, $¥$ ADAS Gleadthorpe, Meden Vale, Mansfield, Nottinghamshire NG20 \\ 9PF, UK, §Division of Environmental Science, School of Biological Sciences, University of Nottingham, Sutton Bonington \\ Campus, Loughborough, Leicestershire LE12 5RD, UK
}

\begin{abstract}
The potential impact of climate change by the year 2050 on intensive livestock systems in Britain is assessed through the use of simulation models of farming systems. The submodels comprise livestock feeding, livestock thermal balance and the thermal balance of controlled environment buildings and a stochastic weather generator. These are integrated to form system models for growing pigs and broiler chickens. They are applied to scenarios typical of SE England, which is the warmest region of the country and represents the worst case. For both species the frequency of severe heat stress is substantially increased, with a consequent risk of mortality. To offset this, it would be necessary to reduce stocking densities considerably, or to invest in improved ventilation or cooling equipment. Other effects on production are likely to be small.
\end{abstract}

Keywords: buildings, climate change, physiology, pigs, poultry

Received 5 November 1999; revised version received 4 August and accepted 17 August 2000

\section{Introduction}

Numerous experimental and modelling studies have attempted to assess the likely effects of global climate change on agricultural crops in Britain and elsewhere. A smaller number have investigated the indirect effects on livestock produced by changes in the survival of pathogens, disease vectors and parasites. Some have also considered the effects of changes in forage crop productivity and seasonality; the project funded by the Scottish Office Agriculture, Environment and Fisheries Department (MacKerron 1996) is of particular relevance. However, few, if any, have considered the impact of climate change on livestock production systems through both the direct effects of temperature stress and indirect effects through forage production.

The objectives of this paper and its companion (Parsons et al. 2000) are to indicate the likely changes in the sustainability of different enterprises across England and Wales and to attempt to draw conclusions about possible changes in regional patterns of agricultural land use that may result. Thus models have been created of

Correspondence: fax +44/ 1525860156 , e-mail david.parsons@ bbsrc.ac.uk livestock systems using, as far as possible, existing submodels of the component processes, which are then applied across a range of geographical and climatological scenarios.

This paper describes the component models for intensive livestock systems and how they were integrated. The components are livestock feeding, thermal balances of pigs and poultry, and controlled environment building and a stochastic weather generator. The results are presented and the possible implications are discussed.

\section{Component models}

Growing pig feeding model

The growing pig model is based on the one described by Stranks et al. (1988). The ability of the pig to grow is based on its protein deposition rate, which is dependent on the breed and sex of the pig. The model simulates the growth of the pig from a weight of around $20 \mathrm{~kg}$ until it reaches its target weight, using the factorial approach (ARC 1981). 
The pig has a metabolizable energy (ME) intake (or appetite),

$$
E=2.0 w^{0.63},
$$

where $E$ is the intake (MJ day ${ }^{-1}$ ) and $w$ is the liveweight $(\mathrm{kg})$. This intake will be used for maintenance and growth. The energy used for the growth of the pig is split between that used for protein and fat deposition,

$$
x=\sum E_{i}=\sum \frac{e_{i}}{k_{i}} \quad \text { for } i=m, p, f
$$

where $m$ is maintenance, $p$ is protein and $f$ is fat. The $e_{i}$ are the net energy requirements, the $E_{i}$ are the feed ME requirements and the $k_{i}$ are the conversion efficiencies. The ME used for maintenance is

$$
e_{m}=0.719 w^{0.63} \text {. }
$$

The efficiency $\left(k_{m}\right)$ is taken to be 1.0, because all energy for maintenance is ultimately converted to heat.

The protein deposition rate, $\Delta w_{\mathrm{p}}\left(\mathrm{g} \mathrm{day}^{-1}\right)$, varies according to

$$
\Delta w_{p}=\Delta \hat{w}_{p}-0.95^{w}\left(0.5 \Delta \hat{w}_{p}-25\right)
$$

where $\Delta w_{\mathrm{p}}$ is the maximum protein deposition rate, typically in the range $110-130 \mathrm{~g} \mathrm{day}^{-1}$. The energy required to deposit the protein is

$$
e_{p}=24.7 \Delta w_{p},
$$

with efficiency, $k_{\mathrm{p}}=0.54$. Now, by using the equation above, the surplus energy, $e_{\mathrm{f}}$ to be used for fat deposition can be calculated. Fat is deposited at a rate $\Delta w_{\mathrm{f}}$, which depends on $e_{\mathrm{f}}$, available:

$$
\Delta w_{f}=\frac{e_{f}}{39.7 k_{f}}
$$

where efficiency, $k_{\mathrm{f}}=0.75$.

The model computes the daily liveweight gain of the pig by evaluating the various components: protein, ash, water and fat. Initially the pig's contents are

$$
w_{p}=0.165 w_{0}, w_{a}=0.116 w_{0}, w_{w}=1.02 w_{0}^{0.865},
$$

where $w_{0}$ is the empty-body weight, $w_{\mathrm{a}}$ is the ash and $w_{\mathrm{w}}$ is the water content and the remainder of the initial empty-body weight is fat. The pig is assumed to have undigested food in its gut at all times, so the total weight of the pig is $1.1 w_{0}$.

Now each day the pig will gain protein and fat as shown in the equations above, and the ash gain rate is

$$
0.21 \Delta w_{p}
$$

The water content throughout is,

$$
w_{w}=4.85 w_{p}^{0.865} .
$$

It is assumed that the energy deposited as body tissue is retained. The rest forms the metabolic heat production $Q$,

$$
Q=E_{m}+E_{f}\left(1-k_{f}\right)+E_{p}\left(1-k_{p}\right) .
$$

\section{Broiler chicken feeding model}

The structure of the chicken feeding model is slightly different from the pig model, as it is an empirical model based on data from a number of sources. Broilers typically grow from their hatching weight of about $45 \mathrm{~g}$ to a mature weight of $2.5-3 \mathrm{~kg}$ in about $6-7$ weeks.

The growing weights from six commercial broiler stocks (Hancock etal. 1995) were analysed and the following formula was fitted to the data

$$
w=5.305 \exp (-\exp (-0.00341(t-42.72)))-0.0278,
$$

where $t$ is the age in days since hatching and $w$ is the weight of the chicken $(\mathrm{kg})$. The weight of gut contents, $w_{\mathrm{g}}$, varies as the chicken grows. The following expression was fitted to the data on gut fill from Hancock et al. (1995)

$$
w_{g}= \begin{cases}(0.00281 t+0.0168) w & t \leq 22 \\ 0.076 w & t>22\end{cases}
$$

The body of the chicken is partitioned into its various components of ash, protein, lipid and water in order to calculate the energy requirements. The rate of increase of body protein is

$$
\Delta w_{p}=0.18183 \Delta w_{d}
$$

where $w_{d}$ is the empty gut weight of the chicken. The other components are related to the protein weight: ash

$$
w_{a}=0.21 w_{p}
$$

water (Emmans 1981)

$$
w_{w}=w_{p}\left(2.96-0.3 \ln \left(w_{p} / W_{p}\right)\right),
$$

where $W_{\mathrm{p}}$ is the mature protein weight, typically $0.795 \mathrm{~kg}$, and lipid, which is the remainder of the weight:

$$
w_{f}=w_{d}-w_{p}-w_{a}-w_{w}
$$

The energy used for growth and maintenance is now calculated. The total metabolizable energy, $E\left(\mathrm{MJ} \mathrm{day}^{-1}\right)$ is the sum of the components (Zoons et al. 1991),

$$
E=\sum E_{i}=\sum \frac{e_{i}}{k_{i}} \quad \text { for } i=m, m p, p, f
$$

where $m$ is maintenance, $m p$ is the energy to metabolize protein needed for maintenance, $p$ is energy required for protein deposition and $f$ is the fat. The energy required for fat and protein growth is 39.1 and $23.7 \mathrm{MJ} \mathrm{kg}^{-1}$, respectively, with efficiencies $k_{\mathrm{f}}=0.7, k_{\mathrm{p}}=0.4$. The $\mathrm{ME}$ for maintenance $\left(\mathrm{MJ} \mathrm{day}^{-1}\right)$ is,

$$
e_{m}=0.45 w^{0.75}
$$

and the maintenance protein is

$$
\mathrm{p}_{\mathrm{m}}=0.00233 \mathrm{w}^{2 / 3}
$$

where the maintenance protein, $p_{\mathrm{m}}\left(\mathrm{kg} \mathrm{day}^{-1}\right)$, requires energy $e_{m p}$ at the same rate as protein growth. 
It is assumed that the energy deposited as body tissue is retained. The rest forms the metabolic heat production $Q$,

$$
Q=E_{m}+E_{m p}+E_{f}\left(1-k_{f}\right)+E_{p}\left(1-k_{p}\right) .
$$

For both the pig and broiler feeding models the intake of the animal will be affected by the incidence of stress in the previous day, as described later.

\section{Thermal balance models for pigs and poultry}

The thermal model design for indoor animals was a simplified adaptation of that described in Parsons et al. (2000). The same energy balance relationships, based on the principles of heat transfer, were used, and the outputs were the energy requirement for a specified hourly period, and a quantification of the degree of thermal stress suffered, given the meteorological conditions.

Pigs were modelled as long round-ended cylinders representing head and body, with vertical cylinders representing legs. The pig coat, which is usually sparse, was ignored, and the resulting two-layer energy balance model was much simpler to solve than the three-layer model for outdoor animals. Chickens were modelled as spherical bodies with cylindrical legs and neck. The resistance to heat transfer of the body tissue and feathers was taken as a single value, thereby reducing the chicken to a simple two-layer model. The legs, neck and head were assumed bare, with appropriate values of the tissue resistance to simulate the vasomotor response in the comb, wattles and feet to the environmental conditions. Detailed descriptions of the model design and discussions of the implications can be found in Turnpenny (1997) and Turnpenny et al. (2000 a,b).

Solar radiation was assumed to be zero for animals indoors. Input values of microclimate variables such as air speed and radiant temperature of the environment in the building were obtained from the model of the building energy balance (see section below). The building microclimate is therefore linked to the outdoor climate by the building heat balance. Humidity in the building is affected by the latent heat flux from the animals. The mass flux of water vapour from the animals and, hence, the change in humidity inside the building, were calculated by the model from the latent heat flux.

Other important considerations in modelling the thermal balance of animals indoors are conduction of heat to the ground and to other animals. The current model estimated conductivities from the work by Bruce \& Clark (1979), who used a comprehensive model of pig energy balance. The pig indoors can lose $15 \%$ of its heat through conduction to the floor (Mount 1967). Bruce \& Clark proposed that the heat flux to the floor was
Table 1. Values of lower critical temperature for different classes of animal

\begin{tabular}{lcll}
\hline Animal & Mass $(\mathrm{kg})$ & Age/other comments & LCT $\left({ }^{\circ} \mathrm{C}\right)$ \\
\hline Piglet & 2 & & 30 \\
& & & \\
Pig & 100 & Intake twice maintenance & 19 \\
Chick & 0.036 & 2-6 days & 34 \\
Chicken & 2.4 & 1 years & 16 \\
\hline
\end{tabular}

proportional to the difference between deep body and ambient temperatures, and inversely proportional to the resistance of the floor material, $r_{\text {floor }}$. This is an important input as the insulation provided by concrete is approximately one-sixth that of deep straw. Bruce \& Clark also proposed a semiempirical scheme to allow for conduction from one animal to another, where the area of one animal in contact with other animals is proportional to $N-(1 / N)$, where $N$ is the number of animals housed together. The estimate of contact area does not include a temperature dependence, which is a major failing of the model, as pigs (and chicks) use huddling to prevent excessive heat loss in the cold.

\section{A thermal balance model of a controlled environment building}

In general, pigs and poultry are kept in controlledenvironment buildings all year round. Their microclimate is regulated closely for temperature, light and ventilation. Within an animal's thermoneutral zone metabolic heat production and energy expenditure are minimal and the animal is assumed 'thermally comfortable'. The zone is bounded by the lower critical temperature (LCT) and the upper critical temperature (UCT). The animals will also become stressed thermally if the humidity in the building is too high. The lower critical temperatures for day old and mature pigs and chickens are shown in Table 1 (Clark \& McArthur 1994). Charles (1981) recommends housing pigs at $3 \mathrm{~K}$ above their lower critical temperature. The recommended temperature for broilers over 3 weeks is $21^{\circ} \mathrm{C}$. The pig's LCT depends on its age, growth rate and the building's floor material. The following equation was fitted for the LCT of pigs fed at three times maintenance and housed on concrete slats,

$$
T_{L C}=16 \exp ^{-0.04} w+282
$$

where $w$ is the pig's live weight $(\mathrm{kg})$ and $T_{\mathrm{LC}}$ is the lower critical temperature $(\mathrm{K})$.

There are two ventilation limits needed for a controlled environment building (Table 2). The maximum ventilation requirement is the amount of air necessary to 
Table 2. Typical ventilation rate requirements $\left(\mathrm{m}^{3} \mathrm{~s}^{-1}\right.$ animal $\left.^{-1}\right)$

\begin{tabular}{lcl}
\hline Animal & Minimum & Maximum \\
\hline Pig & $53 \times 10^{-4}$ & $53 \times 10^{-3}$ \\
Broiler & $2.9 \times 10^{-4}$ & $24 \times 10^{-4}$ \\
\hline
\end{tabular}

prevent the building overheating and the minimum ventilation requirement is the amount of air needed to maintain healthy amounts of oxygen, carbon dioxide and ammonia and sufficiently reduce the humidity in the building. The maximum pig ventilation rate is based on a finishing weight of $100 \mathrm{~kg}$ (Randall 1977) whilst that for broilers is based on the weight of a fully grown bird (Charles 1981).

The model for the thermal balance of the controlled environment building is similar to the one used by Cooper et al. (1998) for naturally ventilated buildings. The model calculates steady-state heat balances every hour. Livestock buildings used to house pigs and poultry have ventilation systems in the buildings in which fans are controlled automatically such that a desired house temperature is maintained.

The temperature of the building is related to the ambient temperature and ventilation rate by the equation,

$$
Q=1200 V \Delta T+U A \Delta T
$$

where $Q$ is the sensible heat output per animal $(W), \Delta T$ is the temperature lift above the outside temperature $(\mathrm{K}), V$ is the ventilation rate in $\mathrm{m}^{3} \mathrm{~s}^{-1}$ per animal, $U$ is the average thermal transmittance of walls and roof $\left(\mathrm{Wm}^{-2}\right.$ $\mathrm{K}^{-1}$ ) and $A$ is the exposed area of walls and roof per animal in square metres (Charles 1981).

The heat output of the animal is calculated in the feeding model. This heat output can be divided into dry (sensible) heat and latent heat. The latent heat is the evaporative heat loss through panting and sweating by the animal.

In the model the temperature of the house is controlled by first calculating the temperature of the house at maximum and minimum ventilation rates and interpolating between the two to reach the ventilation rate that gives the desired temperature, unless one of the limits is reached.

The absolute humidity $\left(\mathrm{kg} \mathrm{kg}^{-1}\right)$ of the building is calculated each hour for the building using the equation,

$$
\frac{d h_{i}}{d t}=\frac{n m(t)}{\rho v}+\frac{\left(h_{o}-h_{i}\right) V_{t}}{v}
$$

where $h_{\mathrm{i}}$ and $h_{\mathrm{o}}$ are the internal and outside humidities, respectively, $n$ is the number of animals in the house, $m(t)$ is the mass flux of water vapour from one animal, and $v$ is the volume of the house.

\section{System model}

\section{Model structure}

In order to evaluate the performance of livestock systems under future climatic scenarios the individual models needed to be integrated into a system model, known as ECCLIPS (Effect of Climate Change on Livestock Production Systems). The interaction between the submodels is shown in Fig. 1. Each day the animal feeding model calculates the growth during the day for the animal and its rate of metabolic heat production. The weight and heat production rate are then treated as constant throughout that day for the heat balance models. The building model operates on a time step of $1 \mathrm{~h}$ and is driven by the weather data, the total metabolic heat production and the latent heat production to calculate the internal temperature and humidity. The livestock heat balance model uses the metabolic heat production and environmental information to calculate the rate of heat loss, and hence the degree of heat or cold stress.

As described above, the building ventilation rate is adjusted to keep the temperature in the desired range simulated as far as possible. The systems in the model represent typical current practice, but an important question is whether they will be adequate for future scenarios. Failures to sustain the lower critical temperature are not considered by the models, because the future climatic scenarios all contain increased temperatures, so cold stress would be expected to be a less frequent problem. More relevant is heat stress, which reduces the animal's appetite and consequently reduces their rate of growth. As noted in Parsons et al. (2000) it was difficult to find suitable experimental data to derive a model, so the same assumption is made here: intake is reduced by $2 \%$ for each hour of severe stress, up to a maximum of $16 \%$.

The models are run for one year consisting of several production cycles. The pigs typically reach a slaughter weight in $14-15$ weeks, so there are about $3 \frac{1}{2} 2$ cycles per year. The poultry require 6-7 weeks with an interval of 2 weeks between batches, resulting in 6 cycles. All cycles were started on 1 January to use the 1-year sets of data produced by the stochastic weather generator (Parsons et al. 2000).

\section{Inputs to ECCLIPS}

ECCLIPS uses inputs defined for all the component models. Any of these inputs can be simply changed by 
Fig. 1 Schematic of the intensive livestock integrated model

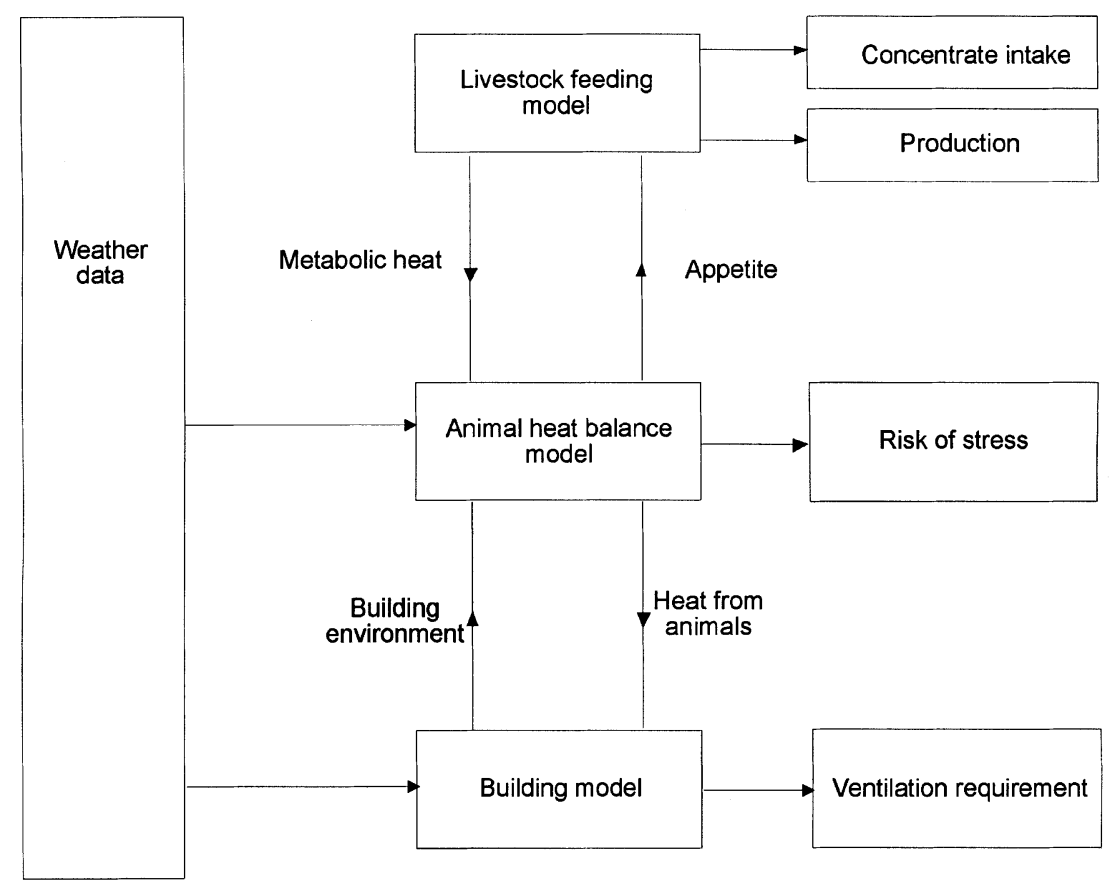

altering the appropriate input file. The main inputs for each of the modules are as follows:

System: Weather dataset, year, duration of run

Building model: Dimensions and orientation of building, $U$-values of walls and roof

Thermal balance model: Length, thermal and mechanical properties of coat or feathers, deep body temperature, tissue insulation for parts of the body.

Animal feeding model: Number of animals, initial live weight, target weight

\section{Output}

All of the component models provide yearly and daily output. The yearly output provides 'risk' and 'productivity' variables. The productivity outputs are yield, intake and final weight. The risk outputs are the frequency of stress and the number of hours for which the ventilation system at maximum rate cannot control the internal temperature of the house below the level that causes heat stress.

\section{Results}

The results are presented for each of the enterprise types in a common format: a table of the main variables that describe the systems, a table of the main performance measures, and a discussion of the main points. As in the companion paper (Parsons etal. 2000), the results are shown for the IPCC baseline scenario IS92a (IPCC 1992) in the year 2050 only, because it was found that the variation between the results of the scenarios was always negligible. In contrast to that paper, only the eastern lowland site (Boxworth, Cambridgeshire) is considered, because topography, soil type and rainfall are unimportant for intensive livestock. Some of the other weather variables that show regional variations, particularly temperature, humidity and windspeed, do have some effect and, in this respect, Boxworth represents the worst case, because it has the highest mean temperatures.

Again, as far as possible the farming scenarios were chosen to reflect typical current practice. The measures of heat stress used are indicators of the physiological state of the animals and we proceed on the same assumption, that present levels are tolerable, but that substantial increases would be unacceptable. This certainly appears to be the case for broilers, where mortality rates already increase during warm summers.

All the results are shown as means and standard deviations, but these should not be used for conventional significance tests for two reasons. First, the data are the results of deterministic models acting on data generated by stochastic weather generators, so they have unusual statistical properties. Secondly, there are dependencies between years in the different scenarios, invalidating the independence assumptions on which conventional analyses are based. In general, the results obtained actually have greater significance than would be indicated by hypothesis testing, because a change in the mean value is actually an indication of a change in the whole distribu- 
tion. Thus, for example, if the variance is unchanged, a $20 \%$ increase in the mean frequency of heat stress also implies a $20 \%$ increase in the upper quartile, and so on.

As in Parsons etal. (2000), some of the results for key variables are also shown as graphs in which the results for individual years are ranked by the dependent variable, allowing visual assessments of stochastic dominance and the relative frequencies of events to be made.

\section{Intensive pigs}

The growing pig system is simulated for a year in which 3.5 crops of pigs are reared. The results are shown in Tables 3 and 4 . The frequency of heat stress increased by over $20 \%$, despite an increase in the use of energy for ventilation of $10 \%$. Figure 2 (a) clearly shows the increased frequency of stress: it can be observed that the present median is exceeded in all but one of the runs for 2050. The increased use of energy for ventilation is shown in Fig. 2(b). Increased stress resulted in a small reduction in total livestock production and concentrate intake. Under the climate change scenario the piglets took almost half a day longer to reach their target weight as a consequence of the reduction in intake caused by heat stress. The livestock produced varied less from yearto-year than for the grazing livestock.

There was no change in the estimated gross margin per piglet because the effect of stress on growth rate was small. Reducing the growth rate significantly would have the effect of increasing the feed required to reach the target weight, because the daily maintenance requirement must be supplied for a longer period. It is possible that the feedback mechanism in the model from stress to intake is too weak, but better data would be required to establish this. It is also difficult to quantify the effects that an increase of heat stress would have on mortality rate, which, in an extremely hot year, would significantly lower production. If the stocking density were reduced sufficiently to reduce the level of heat stress to the present value, the gross margin per house would be significantly reduced. The model assumes no provision for wallowing, which could be used to alleviate heat stress. Alternatively ventilation could also be improved, which would require capital investment and could increase the running costs.

\section{Broiler hens}

The broiler house is also simulated for one year, so there are 6 crops of birds with a changeover time between crops of two weeks. The results are shown in Tables 5 and 6. The occurrence of warmer temperatures caused the frequency of heat stress of the birds to increase by
Table 3. Main input variables for pig scenarios

Boxworth

$\begin{array}{lr}\text { Number of pigs } & 640 \\ \text { Age at slaughter (day) } & 105 \\ \text { Duration of model run (day) } & 365 \\ \text { Initial liveweight }(\mathrm{kg}) & 20 \\ \text { Target liveweight }(\mathrm{kg}) & 100 \\ \text { Building area }\left(\mathrm{m}^{2}\right) & 480\end{array}$
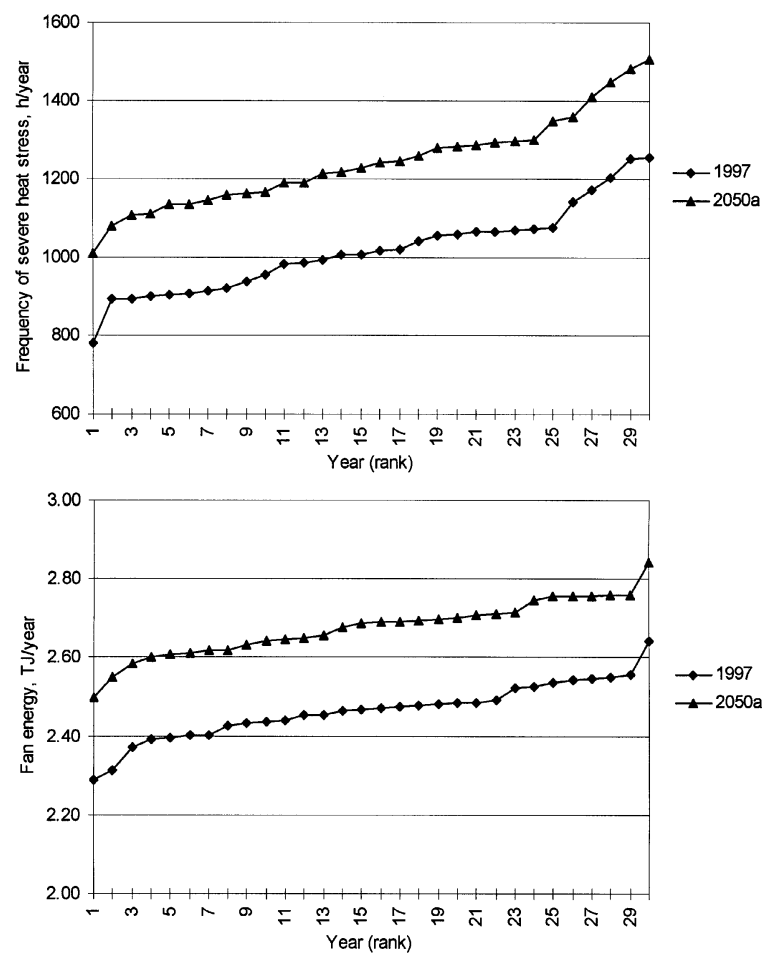

Fig. 2 Results of growing pig simulation for 30 years at Boxworth, comparing baseline (1997) and modified (2050 IS92a) climates, ranked by the dependent variable: (a) Frequency of severe heat stress; (b) Total energy consumed by ventilation fans

Table 4. Performance measures for pig scenarios, mean (standard deviation)

\begin{tabular}{lcc}
\hline & \multicolumn{3}{c}{ Boxworth } \\
\cline { 2 - 3 } & Baseline & IS92a \\
\hline Total liveweight production $\left(\mathrm{t} \mathrm{y}^{-1}\right)$ & $359(1)$ & $357(1)$ \\
Concentrate intake $\left(\mathrm{kg} \mathrm{pig}^{-1}\right)$ & $200(1)$ & $199(1)$ \\
Severe stress $\left(\mathrm{h} \mathrm{y}^{-1}\right)$ & $1018(112)$ & $1242(119)$ \\
Fan energy (MJ pig & \\
Gross margin $\left(£\right.$ pig $\left.^{-1}\right)$ & $64.75(2)$ & $71(2)$ \\
\hline
\end{tabular}


Table 5. Main input variables for broiler scenarios

\begin{tabular}{lr} 
& Boxworth \\
\hline Number of birds & 10,000 \\
Age at slaughter (day) & 46 \\
Duration of model run (day) & 365 \\
Initial liveweight (g) & 260 \\
Target liveweight $(\mathrm{g})$ & 2200 \\
Building area $\left(\mathrm{m}^{2}\right)$ & 480 \\
\hline
\end{tabular}

Table 6. Performance measures for broiler scenarios, mean (standard deviation)

\begin{tabular}{lcc}
\hline \multicolumn{3}{c}{ Boxworth } \\
\cline { 2 - 3 } & Baseline & IS92a \\
\hline Total liveweight production & & \\
$\left(\mathrm{t} \mathrm{y}^{-1}\right)$ & $133.7(0.5)$ & $133.9(0.4)$ \\
Concentrate intake $\left(\mathrm{kg} \mathrm{bird}^{-1}\right)$ & $4.84(0.0)$ & $4.85(0.0)$ \\
Severe stress $\left(\mathrm{h} \mathrm{y}^{-1}\right)$ & $1415(98)$ & $1539(91)$ \\
Fan energy $\left(\mathrm{MJ} \mathrm{bird}^{-1}\right)$ & $0.72(0.0)$ & $0.81(0.0)$ \\
Gross margin $\left(£\right.$ bird $\left.^{-1}\right)$ & $0.228(0.0)$ & $0.226(0.0)$ \\
\hline
\end{tabular}
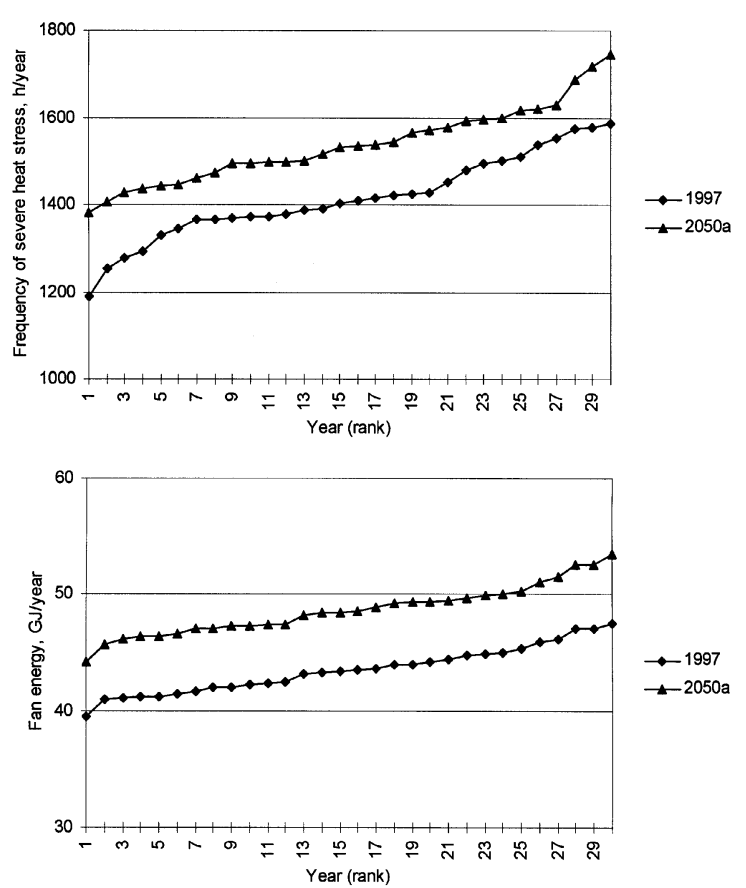

Fig. 3 Results of broiler hen simulation for 30 years at Boxworth, comparing baseline (1997) and modified (2050 IS92a) climates, ranked by the dependent variable: (a) Frequency of severe heat stress; (b) Total energy consumed by ventilation fans

about $10 \%$ despite a $10 \%$ increase in the energy consumption for ventilation. However, a better measure

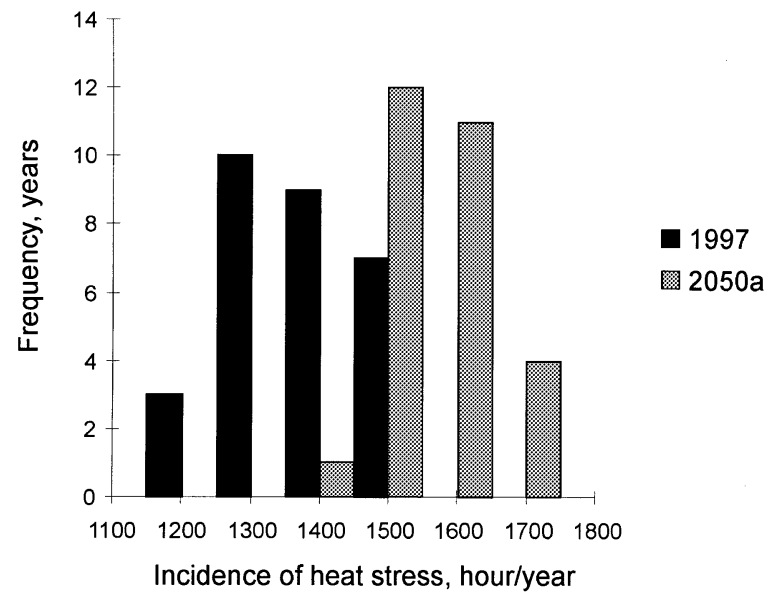

Fig. 4 Distribution of incidence of heat stress for broilers under present and changed climates

for broilers is the frequency with which the temperature in the house exceeds the bird's upper critical temperature by more than $3 \mathrm{~K}$. This frequency increased by $30 \%$ under the climate change scenario, which could lead to substantially larger mortality rates. Figure 3(c) shows a very similar pattern to that found for pigs: again the present median is exceeded in 29 of the 30 simulations for 2050. The pattern of energy consumption (Fig. 3b) is also similar to that found for pigs. Transforming the stress data into a histogram (Fig. 4) makes the shift in the distribution clearer. There was no change in the total liveweight production, while each crop of broilers took about a day longer to reach their target weight of $2.2 \mathrm{~kg}$. The comments about modelling the effects of heat stress in pigs also apply to broilers. There was a negligible change in the concentrate intake.

The gross margin per bird was reduced by less than $1 \%$, however, this makes no allowances for the increases in mortality rate resulting from heat stress, especially in years of extremely high temperatures. A reduction in the stocking density of $12 \%$ was required to reduce frequency of heat stress to the baseline level. Clearly this would entail a corresponding fall in output. Alternatively, because the ventilation was restricted by the capacity of the fans, additional capital investment could be used to improve it. Some producers are already installing reversible fans or circulation fans in broiler houses to increase convective cooling by raising the air speed.

\section{Discussion}

Most of the points discussed in Parsons et al. (2000) concerning the difficulty of integrating disparate models apply to the intensive livestock models also. However, in 
general, the problems were less severe because of the absence of the grass production model, the use of single component diets and the presence of controlled ventilation. The largest uncertainty in the data was between the growth rates of modern broilers and those used in earlier metabolic studies which provided parameters for the heat balance model.

Both this paper and Parsons etal. (2000) have shown small or negligible changes in the gross margins for the enterprises considered, except for the unknown potential changes in mortality rates. In practice, these would be obscured by larger economic changes. Even in the short term, in a stable climate, prices are highly variable and subject to external forces, such as world commodity prices (as seen in the UK during 1998), the General Agreement on Tariffs and Trade and the European Union's Common Agricultural Policy. In addition, any effects of climate change on cereal prices would have direct consequences for livestock feeds. The implications of increased levels of heat stress for health, welfare and capital investment are likely to outweigh the changes in growth and feeding.

\section{Conclusions}

1 Heat stress is likely to become a serious risk factor causing increased mortality for intensive livestock, especially broilers, unless there is investment in improved ventilation and cooling systems.

2 Other than the mortality risk, the changes in gross margin found are negligible compared with those induced by external economic factors.

3 However, increased capital investment in ventilation and cooling systems will probably be needed.

\section{Acknowledgements}

This project was funded by the UK Ministry of Agriculture, Fisheries and Food under the Impacts of Climate Change research programme, as contract CSA2523/CC0315.

Some of the weather data used in the development and validation of the models used in this project were provided by the Meteorological Office, Bracknell.

SPECTRE was provided by the Climatic Research Unit (CRU) at the University of East Anglia, and we would like to thank Dr David Viner of CRU for his advice and assistance in the interpretation of the climatic scenarios.

We would also like to thank Anton de Baets, who assisted in the analysis of the results while on placement at Silsoe Research Institute from Wageningen Agricultural University.

\section{References}

ARC (1981) The Nutrient Requirements of Pigs. Commonwealth Agricultural Bureaux, Slough.

Bruce JM, Clark JJ (1979) Models of heat production and critical temperature for growing pigs. Animal Production, 28, 353-369.

Charles DR (1981) Practical ventilation and temperature control for poultry. In: Environmental Aspects of Housing for Animal Production (ed. Clark JA), pp. 183-197. Butterworth, London.

Clark JA, McArthur AJ (1994) Thermal Exchanges. In: Livestock Housing (eds Wathes CM, Charles DR), pp. 183-246. Commonwealth Agricultural Bureaux, Oxford.

Cooper K, Parsons DJ, Demmers T (1998) A Thermal balance model for livestock buildings for use in climate change studies. Journal of Agricultural Engineering Research, 69, 43-52.

Emmans GC (1981) A model of the growth and feed intake of ad libitum fed animals, particularly poultry. In: Computers in Animal Production (eds Hillyer GM, Whittemore CT, Gunn RG), Occasional publication no. 5, pp. 103-110. British Society of Animal Production, Thames Ditton.

Hancock CE, Bradford GD, Emmans GC, Gous RM (1995) The evaluation of the growth parameters of six strains of commercial broiler chickens. British Poultry Science, 36, 247-264.

IPCC (1992) Climate Change 1992: the Supplementary Report to the IPCC Scientific Assessment. Cambridge University Press. Cambridge, 200pp.

MacKerron DKL (eds) (1996) Special issue: climate change from impact to interaction. Agricultural and Forest Meteorology, 79 (4).

Mount LE (1967) The Heat Loss from New-Born Pigs to the Floor. Research Veterinary Science, 8, 175-186.

Parsons DJ, Armstrong AC, Turnpenny JR, Matthews AM, Cooper K, Clark JA (2001) Integrated models of livestock systems for climate change studies. 1. Grazing systems. Global Change Biology, 7, 93-112.

Randall JM (1977) A Handbook on the Design of a Ventilation System for Livestock Buildings Using Step Control and Automatic Vents. National Institute of Agricultural Engineering, Bedford, 7, 93-112.

Stranks MH, Cooke BC, Fairburn CB et al. (1988) Nutrient allowances for growing pigs. Research and Development in Agriculture, 5 (2), 71-88.

Turnpenny JR (1997) Potential impact of climate change on the energy balance of UK livestock. PhD Thesis, University of Nottingham.

Turnpenny JR, McArthur AJ, Clark JA, Wathes CM (2000a) Thermal balance model of livestock. 1. A parsimonious model. Agricultural and Forest Meteorology, 101, 15-27.

Turnpenny JR, McArthur AJ, Clark JA, Wathes CM (2000b) Thermal balance model of livestock. 2. Applications of a parsimonious model. Agricultural and Forest Meteorology, 101, $29-52$.

Zoons J, Buyse J, Decuypere E (1991) Mathematical models in broiler raising. World Poultry Science, 47, 243-255. 